\title{
STABILITY INDICATING RP-HPLC METHOD FOR DETERMINATION OF AMISULPRIDE IN TABLET DOSAGE FORM
}

\author{
Sunil Singh* \\ Department of Pharmaceutical Chemistry, Ideal Institute of Pharmacy, Wada, Palghar-421303, \\ Maharashtra, India \\ ${ }^{*} E$-mail: rssuni129@rediffmail.com \\ Tel.: +918224874888.
}

Received: Dec 01, 2019 / Revised: Dec 28, 2019 / Accepted: Dec 29, 2019

\begin{abstract}
A new stability indicating RP-HPLC method was development and validation done for Amisulpride in tablet dosage form. RP-HPLC method was performed for estimation of dosage form and degradants. The method utilizes a mobile phase Acetonitrile:water in the ratio of $60: 40 \mathrm{v} / \mathrm{v}$ and a flow rate of 1 $\mathrm{ml} / \mathrm{min}$ with the UV detection at $226 \mathrm{~nm}$ for Amisulpride (AMP). The retention time was found to be 4.635 min for Amisulpride. The linearity was found to be in the concentration range of $5-30 \mathrm{pg} / \mathrm{ml}$ $\left(r^{2}=0.999\right)$ for AMP. Forced degradations were carried out under acid, base, thermal, photolytic and oxidative stress conditions. The method was satisfactorily validated as per the ICH guideline.
\end{abstract}

Key words: Amisulpride, RP-HPLC, Forced degradation study, Validation, ICH guideline.

\section{INTRODUCTION}

Amisulpride (AMS) is chemically, 4-amino-N$\{[(2 \mathrm{RS})$-1-ethyl pyrolidin-2-yl]methyl $\}$-5(ethyl sulphonyl)-2-methoxy benzamide (Figure 1) (Sweetman, 2002; O'neil, 2006; BP, 2006) and used in treatment of schizophrenia. It has high affinity for dopamine D2/D3 receptors. Literature survey revealed different analytical methods for the estimation of Amisulpride in biological systems like HPLC using either UV or fluorescence detection and an IR, UV spectrophotometric and HPLC method are also reported. A UV spectrophotometric method, a chromatographic method and few electrophoretic methods are also reported for the quantitative estimation of Amisulpride in pharmaceutical formulations (Sachse et al 2003; Skibiński et al 2007; Ravisankar and Devala Rao, 2015a; 2015b; Ascalone et al 1996). The stability-indicating assay is a method that is employed for the analysis of stability samples in pharmaceutical industry. Stability testing plays an important role in the process of drug development. The purpose of stability testing is to provide confirmation on how quality of a drug substance varies with time under the influence of a variety of environmental factors such as temperature, humidity, and light and enables recommendation of storage conditions, and shelf life to be established. The method is expected to allow analysis of individual degradation products (Q1A(R2), 2003; Bakshi and Singh, 2012).<smiles>CCN1CCCC1CNC(=O)c1cc(S(=O)(=O)CC)c(N)cc1OC</smiles>

Fig. 1. Chemical structure of Amisulpride 
MATERIALS AND METHODS

\section{Chemicals}

Methanol used was of HPLC grade. All other reagents used were of analytical grade for the forced degradation studies. The pharmaceutical dosage form used in this study was Sulpitac labelled to contain $200 \mathrm{mg}$ of Amisulpride per tablet, purchased from local market.

\section{Apparatus}

A RP-HPLC (Shimadzu-20 AD) with PDA detector was utilized. An electronic balance (Roy electronics- LCBCN5) was used for weighing the samples. Hot air oven (Coslab CLE-101) was used for the thermal degradation study. A Sonicator (Labfit) was also used.

\section{Preparation of standard stock solutions}

Stock solution of AMP $(1000 \mu \mathrm{g} / \mathrm{ml})$ was prepared by dissolving $100 \mathrm{mg}$ of AMP in $75 \mathrm{ml}$ of methanol in a $100 \mathrm{ml}$ volumetric flask, volume was made up to the mark with methanol to get solution of strength $1000 \mu \mathrm{g} / \mathrm{ml} .10 \mathrm{ml}$ of the solution was pipetted out from $1000 \mu \mathrm{g} / \mathrm{ml}$ solution and transferred to $100 \mathrm{ml}$ volumetric flask and volume was made up with methanol up to the mark, and final dilution was $100 \mu \mathrm{g} / \mathrm{ml}$ solution of AMP.

\section{Selection of sampling wavelengths}

The equivalent of $200 \mathrm{mg}$ of AMP was accurately weighed in $100 \mathrm{ml}$ volumetric flasks separately. After the immediate dissolution, the volume was made up to the mark with solvent. These standard stock solutions were observed to contain $100 \mu \mathrm{g} / \mathrm{ml}$ of AMP. From the above stock solution, working standard solutions having concentration of $5 \mu \mathrm{g} / \mathrm{ml}$ was prepared by appropriate dilution. Working standard solutions of $5 \mu \mathrm{g} / \mathrm{ml}$ of the drug were scanned in the range $400-200 \mathrm{~nm}$ in the spectrum mode at the low scan speed to obtain the overlain spectra of these drugs (Figure 2).

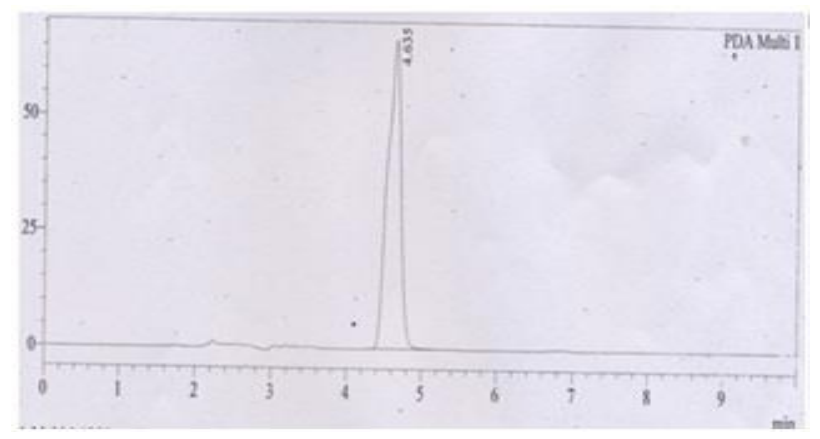

Fig. 2. Chromatogram of AMP in mobile phase

\section{Selection of mobile phase and optimization of method}

Different column chemistry, solvent type, solvent strength, detection wavelength and flow rate were varied to determine the chromatographic conditions giving the best separation. The mobile phase conditions were optimized so that the components were not interfered with the solvent and excipients. Appropriate $\mathrm{k}$ range for eluted peaks, assay sensitivity, solvent noise and use of the same solvent system for extraction of drug from formulation matrices during drug analysis were also considered.

A series of aqueous mobile phases containing methanol, acetonitrile, water were also tested. The best results were obtained when acetonitrile and water solvents were used. Further, the method was optimized by changing the concentration of mobile phase and the results were reported.

From the study, it was found that best result was obtained in a quality separation in terms of peak symmetry, reasonable run time and other parameters by use of $50: 50(\mathrm{v} / \mathrm{v})$ ratio mixture of Acetonitrile:water as mobile phase. The flow rate was determined by testing the effect of different flow rate on the peak area and flow rate of $1 \mathrm{ml} / \mathrm{min}$ was found optimum.

\section{Preparation of standard stock solutions for linearity study}

From the standard stock solutions of 1000 $\mu \mathrm{g} / \mathrm{ml}$, different dilutions were prepared for each drug having concentration. Then, $20 \mu \mathrm{l}$ of these solutions were injected into the LC system with the help of Hamilton syringe. The chromatograms were recorded at $299 \mathrm{~nm}$. From the chromatogram, it was cleared that AMP retention time was 4.635 min from which their area was noted and calibration curve was plotted between the peak area against their respective concentrations. From the calibration curve, it was cleared that AMP has linearity range between $5-25 \mu \mathrm{g} / \mathrm{ml}$ (Figure 3).

\section{Analysis of tablet formulation}

As the result of standard analysis found satisfactory, the method was applied for the quantitative study of this drug in commercially available tablet. For the preparation of the stock solution of tablet dosage form, 20 capsules of Sulpitac were taken and their average weight was determined, after which they were crushed to fine powder. Then, powder equivalent to 40 mg of AMP was taken in $50 \mathrm{ml}$ volumetric flask 


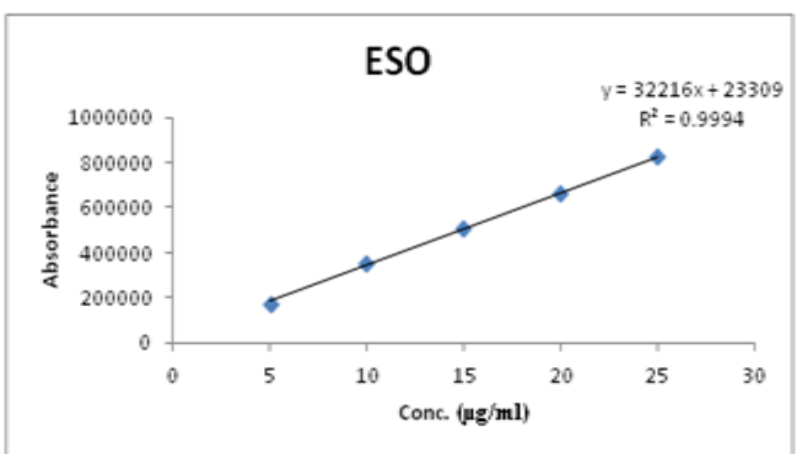

Fig. 3. Calibration curve of AMP in mobile phase

and dissolved in $30 \mathrm{ml}$ of methanol with vigorous shaking for 5-10 min. The supernatant liquid was transferred to $100 \mathrm{ml}$ of volumetric flask through a $0.4 \mu \mathrm{m}$ membrane filter paper. The residue was washed twice with solvent and the combined filtrate was made up to $100 \mathrm{ml}$ mark. $10 \mathrm{ml}$ of the above solution was diluted up to $100 \mathrm{ml}$ solvent. Six replicate of sample solutions were prepared for required concentrations of the three drugs. Then, $20 \mu \mathrm{l}$ of each replicate were injected into the system and their chromatograms were recorded. From the chromatograms, it was observed that AMP was eluted at $4.635 \mathrm{~min}$. The concentrations of these drugs were extrapolated from their respective calibration curves by using the area.

\section{Recovery study}

\section{Linearity and range}

The six point calibration curves that were constructed were linear over the concentration range between 5-25 $\mu \mathrm{g} / \mathrm{ml}$ for Amisulpride. This was repeated for 3 times.

\section{Precision}

For evaluation of intraday precision, repeatability of the result was evaluated for the concentration of $10 \mu \mathrm{g} / \mathrm{ml}$ for Amisulpride by 3 replicate determination at interval of $1 \mathrm{hr}$ and for the evaluation of interday precision, repeatability of result was evaluated for concentration of $10 \mu \mathrm{g} / \mathrm{ml}$ for Amisulpride by 3 replicate determination at interval of $1 \mathrm{hr}$ for 3 days.

\section{Limit of detection}

Limit of detection for Amisulpride was found to be $0.31537 \mu \mathrm{g} / \mathrm{ml}$.

\section{Limit of quantification}

Limit of quantification for Amisulpride was found to de $1.05123 \mu \mathrm{g} / \mathrm{ml}$.

\section{Robustness}

Robustness of proposed method was performed by changing the HPLC analyst and remaining condition was keeping constant.

\section{Stability indicating assay method \\ Acid degradation}

In $10 \mu \mathrm{g} / \mathrm{ml}$ solution, Amisulpride added and kept at room temperature for $24 \mathrm{hr}$.

\section{Base degradation}

In $10 \mu \mathrm{g} / \mathrm{ml}$ solution, Amisulpride added and kept at room temperature for $24 \mathrm{hr}$.

\section{Thermal degradation}

About $50 \mathrm{mg}$ of drug substance kept at $60^{\circ} \mathrm{C}$ for $8 \mathrm{hr}$. Then, the solution was prepared to achieve $10 \mu \mathrm{g} / \mathrm{ml}$ for Amisulpride.

\section{Photolytic degradation}

About $50 \mathrm{mg}$ of drug substance was kept directly to the sun light for $12 \mathrm{hr}$. Then, the solution was prepared to achieve $10 \mu \mathrm{g} / \mathrm{ml}$ for Amisulpride.

\section{Statistical analyses}

Means, standard deviation (SD), relative standard deviation (RSD) and linear regression analysis were calculated using Microsoft Excel 2007.

\section{RESULTS AND DISCUSSION}

Many pharmaceutical compounds undergo degradation during storage or even during the different processes of their manufacture. Several chemical or physical factors can lead to the degradation of drugs. Hydrolysis and oxidation are the most famous chemical degradation routes of drugs.

The main classes of drugs that are subject to degradation are esters, amides and lactams. Ester hydrolysis is frequently base catalyzed, which makes the reaction rapid and irreversible.

In the present work, method development for stability indicating estimation of AMP in tablet dosage form in RP-HPLC was performed by using acetonitrile:water as mobile phase in the ratio of $60: 40(\mathrm{v} / \mathrm{v})$ at a flow rate of $1.0 \mathrm{ml} / \mathrm{min}$ and the data are presented in Table 1.

In the method, wavelengths utilized for Amisulpride were $226 \mathrm{~nm}$. The percentage recovery value obtained was within standard limit of $98 \%$ to $101 \%$ for the method which confirmed that the method was accurate and free from any interference of excipients. 
Table 1. Analysis of commercial formulation in capsule dosage form

\begin{tabular}{|c|c|c|c|}
\hline Formulation & Drug & Label claim (mg) & \% Label claim (Mean \pm SD) \\
\hline Tablet & Amisulpride & $200 \mathrm{mg}$ & $98.79 \pm 0.0008$ \\
\hline
\end{tabular}

The low value of standard deviation obtained confirmed precision of the method. The reproducibility, repeatability and accuracy of the proposed method were found to be satisfactory.
Limit of detection and limit of quantitation were calculated and the result was found to be satisfactory. All recovery studies were compiled in the Table 2.

Table 2. Validation parameters for RP-HPLC methods

\begin{tabular}{|c|c|}
\hline \multirow{2}{*}{ Validation parameter } & Mean \pm SD \\
\cline { 2 - 2 } & Amisulpride magnesium \\
\hline Linearity range & $5-25 \mu \mathrm{g} / \mathrm{ml}$ \\
\hline Correlation coefficient & 0.999 \\
\hline Slope & 32216 \\
\hline Intercept & 23309 \\
\hline \multicolumn{2}{|c|}{ Precision } \\
\hline \multicolumn{2}{|c|}{ Interday } \\
\hline $1^{\text {st }}$ day & $99.8 \pm 0.2362$ \\
\hline $2^{\text {2d }}$ day & $100.3 \pm 0.136$ \\
\hline $3^{\text {rd }}$ day & $99.7 \pm 0.321$ \\
\hline \multicolumn{2}{|c|}{ Intraday } \\
\hline $1^{\text {st } h r) ~}$ & $99.8 \pm 0.2362$ \\
\hline $\left.2^{\text {nd }} \mathrm{hr}\right)$ & $100.1 \pm 0.085$ \\
\hline $\left.3^{\text {rd }} \mathrm{hr}\right)$ & $99.9 \pm 0.503$ \\
\hline \multicolumn{2}{|c|}{ Recovery } \\
\hline $80 \%$ & $99.38 \pm 0.0036$ \\
\hline $100 \%$ & $100.98 \pm 0.0049$ \\
\hline $120 \%$ & $101.96 \pm 0.0026$ \\
\hline LOD $(\mathrm{mg} / \mathrm{ml})$ & $0.31537 \mu \mathrm{g} / \mathrm{ml}$ \\
\hline LOQ (mg/ml) & $1.05123 \mu \mathrm{g} / \mathrm{ml}$ \\
\hline Robustness & $107 \pm 0.000974$ \\
\hline \multicolumn{2}{|c|}{} \\
\hline
\end{tabular}

Acidic degradation, alkali degradation, thermal degradation and photolytic degradation were performed successfully by following ICH guideline Q1A (R2) (Table 3).

Table 3. Forced degradation studies

\begin{tabular}{|c|c|c|}
\hline \multirow{2}{*}{ Condition } & Amount found \% $(\boldsymbol{\mu g} / \mathbf{m l})$ & Result (\% degradation) \\
\cline { 2 - 3 } & AMP & AMP \\
\hline Acid degradation & 89.61 & 10.39 \\
\hline Alkaline degradation & 92.35 & 7.65 \\
\hline Thermal degradation & 88.35 & 11.65 \\
\hline Photolytic degradation & 66.36 & 33.64 \\
\hline
\end{tabular}

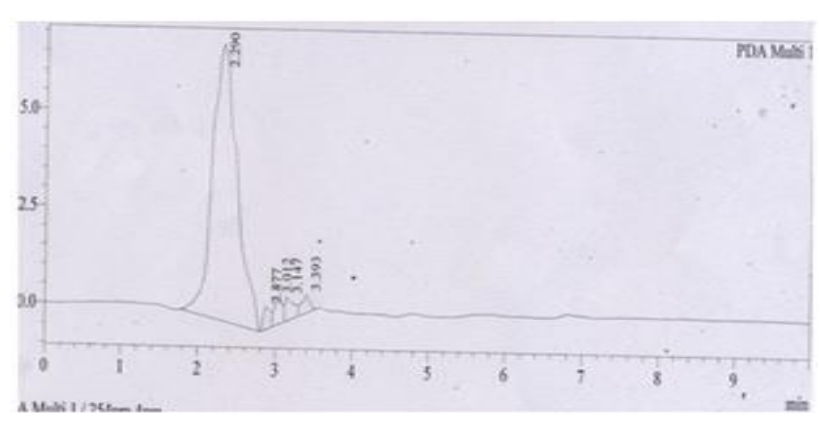

Fig. 4. Acid degradation chromatogram of AMP
Degradation study was conducted for Amisulpride in acidic medium and the results are shown in Figure 4.

Amisulpride when hydrolyzed with alkali, produced their degradation product and the results are shown in Figure 5. Figure 6 shows the thermal degradation of drug AMP and Figure 7 shows the photolytic degradation of drug AMP. Multiple peaks were seen at different time interval in all the chromatograms of AMP. 


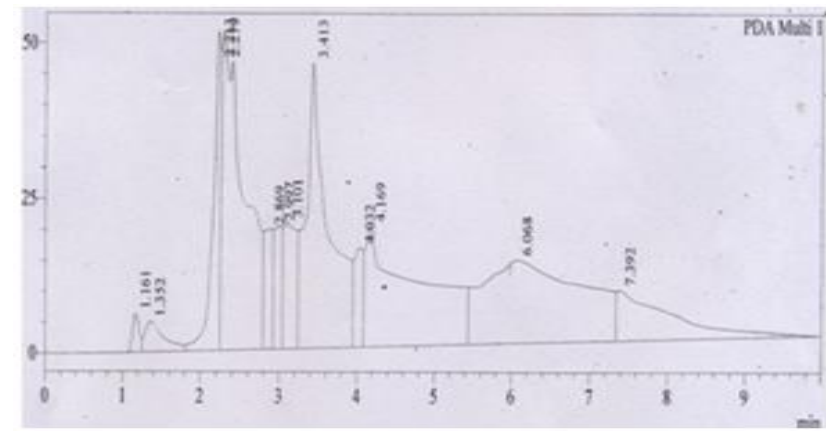

Fig. 5. Alkaline degradation chromatogram of Amisulpride

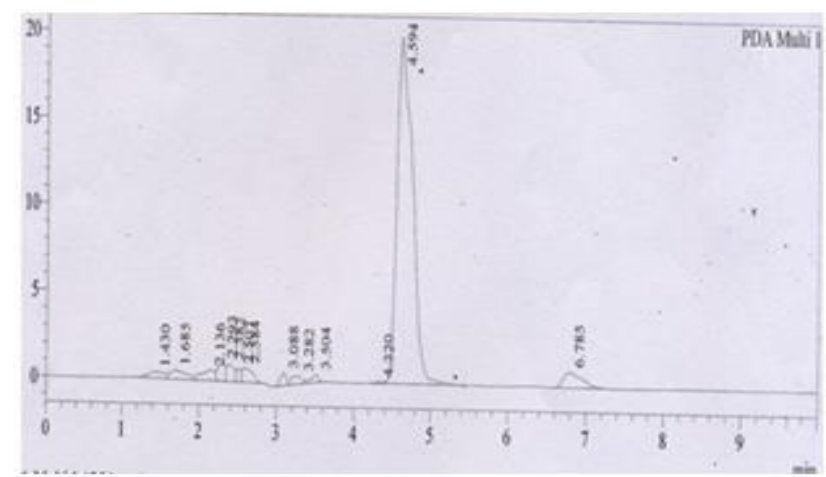

Fig. 6. Thermal degradation chromatogram of Amisulpride

\section{REFERENCES}

Ascalone V, Ripamonti M, Malavasi B. Stereospecific determination of amisulpride, a new benzamide derivative, in human plasma and urine by automated solid-phase extraction and liquid chromatography on a chiral column. application to pharmacokinetics. J. Chromatogr. B. Biomed. Appl. 1996;676(1):95-105. [DOI: 10.1016/0378-4347(95)00418-1]

Bakshi M, Singh S Development of validated stability indicating assay method- critical review. J. Pharm. Biomed. Anal. 2002;28(6):1011-1040. [DOI: 10.1016/S07 31-7085(02)00047-X]

British Pharmacopoeia, The Stationary Office, London, 2006;: 149.

O'neil MJ. The Merck Index - An Encyclopedia for Chemicals, Drugs and Biologicals, Merck and Co., Whitehouse Station, NJ. 2006;14:485.

Q1A (R2). Stability testing of new drug substances and products. International Conference on Hormonization. CPMP/ICH/2736/99, Geneva; 2003.

Sachse J, Härtter S, Weigmann H, Hiemke C. Automated

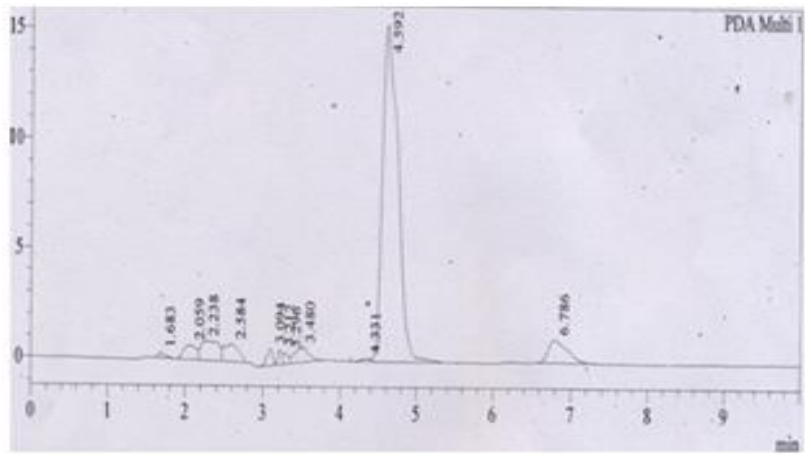

Fig. 7. Photolytic degradation chromatogram of Amisulpride

\section{CONCLUSION}

All these factors lead to the conclusion that the developed stability indicating RP-HPLC method development is accurate, precise, simple, sensitive and rapid and can be applied successfully for the estimation of Amisulpride in tablet dosage form without interference. The relative standard deviation (RSD) for all parameters was found to be less than one, which indicate that the validity of method are also within the limit so the proposed method can be used for routine quantitative estimation of drug.

determination of amisulpride by liquid chromatography with column switching and spectrophotometric detection. J. Chromatogr. B. Analyt. Technol. Biomed. Life Sci. 2003;784(2):405-10. [DOI: 10.1016/s1570-0232(02)008 08-5]

Skibiński R, Komsta Ł, Hopkała H, Suchodolska I. Comparative validation of amisulpride determination in pharmaceuticals by several chromatographic, electrophoretic and spectrophotometric methods. Anal. Chim. Acta 2007;590(2):195-202. [DOI: 10.1016/j.aca.20 07.03.038]

Sweetman S. Martindale - The Complete Drug Reference, Pharmaceutical Press, London. 2002;33:655.

Ravisankar P, Devala Rao G. Novel RP-HPLC method for the determination of Amisulpride in pure and pharmaceutical formulations. J. Chem. Pharm. Res. 2015a;7(6):815-24.

Ravisankar P, Devala Rao G. Novel spectrophotometric methods for the determination of amisulpride in pure and pharmaceutical formulations. Int. J. Recent Sci. Res. 2015b; 6(6):4830-7. 